\title{
Downregulation of Macrophage-Derived T-UCR uc.306 Associates with Poor Prognosis in Hepatocellular Carcinoma
}

\author{
Hong-Lin Luo a,b,c Jie Chen a,c Tao Luo ${ }^{a}$ Fei-Xiang Wua Jun-Jie Liud \\ Hui-Feng Wang ${ }^{a}$ Miao Chen ${ }^{d}$ Le-Qun Lia,b,c Hang Lid \\ aDepartment of Hepatobiliary Surgery, Affiliated Tumor Hospital of Guangxi Medical University, \\ Nanning, bGuangxi Cancer Institute, Nanning, 'Key Laboratory of High-Incidence-Tumor early \\ Prevention and Treatment, Ministry of Education, Nanning, dDepartment of Ultrasound, Affiliated \\ Tumor Hospital of Guangxi Medical University, Nanning, PR China
}

\section{Key Words}

Hepatocellular carcinoma • Transcribed ultraconserved RNAs (T-UCRs) • uc.306 • Cancer survival

\begin{abstract}
Background/Aims: Increasing evidence suggests that T-UCRs are involved in the development of cancer. In this study, we evaluated the role of a macrophage-derived T-UCR, uc.306, in the prognosis of hepatitis B (HBV)-related hepatocellular carcinoma (HCC). Methods: The uc.306 was obtained by screening microassay data obtained during the polarization of U937 cells from the M2 to M1 phenotype. Uc.306 and macrophage molecule markers were detected by qPCR. Immunohistochemical (IHC) assays were used to examine the M1/M2 status of 90 paired HCC tissues. Kaplan-Meier tests and multivariable Cox regression models were used to analyze predictive confidences, survival, and risk factors. Results: In total, 2,977 differentially expressed T-UCRs were obtained, of which 257 showed fold changes $>1.5$. The uc.306 was upregulated in M1 cells and was predicted to be involved in the Wnt pathway. The IHC results showed that M1 macrophages $\left(\mathrm{CD}^{+} 8^{+}\right)$were present in the para-tumor tissues, while the M2 phenotype $\left(\mathrm{CD} 163^{+}\right)$was mainly in the HCC tissues. Uc.306 had a lower expression in the HCC tissues than in that of the para-tumor tissues in 30 paired HCC training sets $(P<0.0001)$, and 252 paired HCC testing sets $(P<0.0001)$. Low expression of uc.306 was significantly associated with a shorter overall survival $(P<0.05)$. Conclusions: The uc.306 may be a promising biomarker for HBV-related HCC, providing a novel marker for the prognosis of HCC.
\end{abstract}

(C) 2017 The Author(s)

Published by S. Karger AG, Basel

\section{Introduction}

Hepatocellular carcinoma (HCC) is one of the most common cancers and the third leading cause of cancer-related death, with rising incidence worldwide [1,2]. Although

H.-L. Luo, J. Chen and T. Luo contributed equally to this article.

Hang Li and Le-Qun Li Department of Ultrasound, Affiliated Tumor Hospital of Guangxi Medical University, Department of Hepatobiliary Surgery, Affiliated Tumor Hospital of Guangxi Medical

University, He Di Rd \#71, Nanning 530021, (People's Republic of China) 


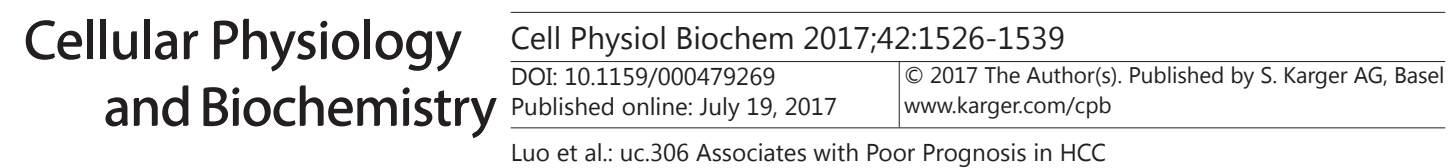

advances have been made in early diagnosis and treatment, especially in surgical techniques, the prognosis of HCC is still poor, with a median survival of 6-20 months. Less than 5\% of the symptomatic patients survive for more than 2 years [3-6]. According to the current guidelines, the curative therapies are mainly restricted to the early stage HCC patients [79]. Therefore, improvements in accurate detection of HCC at early stages, especially among high-risk groups such as cirrhosis or hepatitis patients, are more important in order to improve the treatment and prognosis of the patients $[6,10]$. Studies have shown that the detection of biomarkers associated with HCC in tissues or body fluids is the most promising approach to improve diagnostic accuracy and help HCC patients to receive early therapeutic treatment $[10,11]$.

Non-coding RNAs (ncRNAs) include microRNAs, long non-coding RNAs (lnc-RNA), and transcribed ultra-conserved RNAs (T-UCRs) $[12,13]$. T-UCRs belong to the non-proteincoding DNA group and regulate the expression and translation of mRNAs that are strictly conserved across mice, rats, and humans [14]. Emerging evidence has shown that many T-UCRs act as oncogenes or tumor suppressor genes by post-transcriptionally regulating protein production [15, 16]. Macrophages are immune cells derived from embryonic precursors and circulating $\mathrm{CD} 14^{+}$monocytes that originate from the bone marrow [17], and can be classified into the M1 (classically activated macrophages) and M2 (alternatively activated macrophages) phenotypes [18-21]. Increasing evidence has shown that M2 macrophages are capable of recruiting to the tumor site and increasing tumor angiogenesis $[22,23]$. Studies have also shown that the number of tumor-associated macrophages (TAMs; mainly M2 phenotype) in tumor tissues is associated with poor patient prognosis [24, 25], and tumor promotion [26]. Considering the essential roles of macrophages and T-UCRs in tumors, we measured the expression of T-UCRs in macrophages during the polarization from the M2 to the M1 phenotype. In this study, we detected the differential expression of T-UCRs in M1 and M2 macrophages using a microarray. The uc.306 was chosen because its possible target gene BTRC, which is overlapped with uc.306, may be involved in the Wnt signaling pathway that is closely linked to cancer development and metastasis. The expression of uc.306 in 30 paired HCC tissues and adjacent normal tissues was examined and the association of uc.306 and clinicopathological parameters and overall survival (OS) in 252 HCC patients were further analyzed. To the best of our knowledge, this is the first study investigating the expression and prognostic predictive role of uc.306 in HCC patients. This data may suggest novel markers for the diagnosis and treatment of HCC.

\section{Materials and Methods}

\section{Cell culture and M1/M2 phenotype identification}

U937 cells were plated in 12-well plates and primed with fresh medium supplemented with different stimuli to obtain a gradient of polarity phenotypes. Phorbol 12-myristate 13-acetate (PMA) (100 ng/mL) was added into U937 cells cultured for $24 \mathrm{~h}$, and then interleukin (IL)-4 (20 ng/mL) and IL13 (20 ng/ $\mathrm{mL}$ ) were added to stimulate the differentiation of PMA-primed U937 cells to the M2 phenotype at $12 \mathrm{~h}$ post-incubation. Lipopolysaccharide (LPS) (100 ng/mL) and interferon (IFN)-gamma (20 ng/mL) were used to stimulate cell differentiation from the M2 to the M1 phenotype. The M1 and M2 phenotypes were identified by qPCR analyses of transforming growth factor (TGF)- $\beta$, IL10, IL12, and inducible nitric oxide synthase (iNOS) mRNAs. Replicate samples of polarized M1 and M2 cells were collected and stored at $-80^{\circ} \mathrm{C}$ for subsequent microarray analyses.

\section{LncRNA microarray and data analysis}

Total RNAs were extracted with TRIzol $^{\circledR}$ reagent and the mRNA was purified from total RNA after removal of rRNA (mRNA-ONLY ${ }^{\mathrm{TM}}$ Eukaryotic mRNA Isolation Kit; Epicentre, Madison, WI, USA). RNA quantity and quality were measured by the NanoDrop ${ }^{\circledR}$ ND-1000 (Thermo scientific, Scotts Valley, CA, USA). RNA integrity was assessed by standard denaturing agarose gel electrophoresis. Sample labeling and array hybridization were performed according to the Agilent One-Color Microarray-Based Gene Expression 


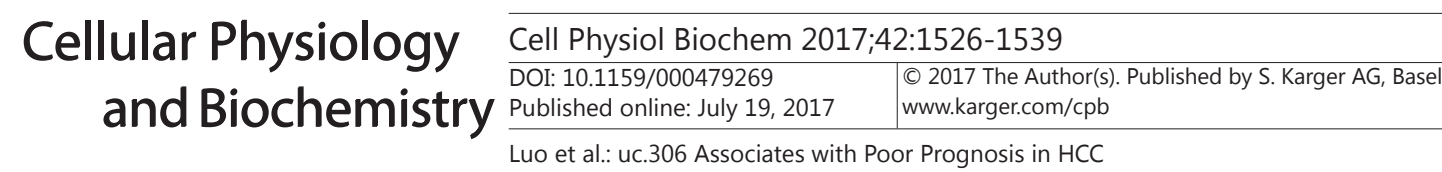

Analysis protocol (Agilent Technology, Santa Clara, CA, USA) with minor modifications. Each sample was amplified and transcribed into fluorescently labeled cRNA along the entire length of the transcripts without 3 ' bias, utilizing a random priming method (Arraystar Flash RNA Labeling Kit; Arraystar, Rockville, MD, USA). The labeled cRNAs were purified by the RNeasy ${ }^{\circledR}$ Mini Kit (Qiagen, Hilden, Germany). The concentration and specific activity of the labeled cRNAs (pmol Cy3/ $\mu$ g cRNA) were measured by the NanoDrop ${ }^{\circledR}$ ND-1000. One microgram of each labeled cRNA was fragmented by adding $5 \mu \mathrm{L} 10 \times$ Blocking Agent and $1 \mu \mathrm{L}$ of $25 \times$ Fragmentation Buffer, then heating the mixture at $60^{\circ} \mathrm{C}$ for $30 \mathrm{~min}$, and finally, $25 \mu \mathrm{L}$ of $2 \times$ GE Hybridization Buffer was added to dilute the labeled cRNA. Fifty microliters of hybridization solution was dispensed into the gasket slide and assembled into the lncRNA expression microarray slide. The slides were incubated for $17 \mathrm{~h}$ at $65^{\circ} \mathrm{C}$ in an Agilent hybridization oven. The hybridized arrays were washed, fixed, and scanned using the Agilent DNA Microarray Scanner (G2565BA; Agilent).

\section{Target gene prediction of specific T-UCR}

Human T-UCRs are listed in website https://users.soe.ucsc.edu/ jill/ultra.html. Totally 482 human T-UCRs are included for now. For each T-UCR, basic information, such as length, region on chromosome and genes near T-UCR and so on are clearly stated. For a specific T-UCR, the up-and down- stream gene or overlapped gene can be checked. For further identification the interaction between T-UCR and its target gene, the online program RPISeq (http://pridb.gdcb.iastate.edu/RPISe) can be used. A value refer to the interaction intensity between T-UCR and its target gene is given, which helps to predict the interaction possibility between T-UCR and its target gene.

\section{Patients and tissue specimens}

A total of 252 pathologically diagnosed HBV-related HCC patients who had undergone surgical resection were recruited by the Affiliated Tumor Hospital of Guangxi Medical University from April 2013 to September 2016. All 252 HCC patients were diagnosed by histopathological examination and the National Comprehensive Cancer Network (NCCN) clinical practice guidelines for oncology. All patients were followed up via telephone or hospital visit until death or at the last time of follow-up in 2016. The patients had a median follow up time of 17.3 months (range, 2-32 months). No patients had a previous cancer diagnosis at the initial screening examination. The clinicopathological characteristics of the patients including age, sex, pathological grades, bio-behavior of the cancer, serum alpha-fetoprotein (AFP) level, hepatic cirrhosis, and radical resection data were obtained from the medical records and pathological reports. The tumor status was classified according to the Barcelona Clinic Liver Cancer (BCLC) staging system. The case endpoint was overall survival (OS), which was calculated from the date of pathological diagnosis/recruitment to death or the end of available follow-up data.

\section{Immunohistochemistry (IHC)}

Ninety HBV-related HCC tissues paired with adjacent normal tissues were fixed with formalin and embedded in paraffin. Samples were sectioned (5 ìm) and coated onto slides. The slides were treated with $3 \% \mathrm{H}_{2} \mathrm{O}_{2}$ at $37^{\circ} \mathrm{C}$ for $1 \mathrm{~h}$ and heated in $10 \mathrm{mM}$ citrate buffer at $120^{\circ} \mathrm{C}$ for $2 \mathrm{~min}$. The primary antibodies, CD68 (Abcam, Cambridge, UK; 1:200 diluted) and CD163 (Abcam; 1:100 diluted), were incubated at $4^{\circ} \mathrm{C}$ overnight, followed by incubation with a secondary peroxidase-conjugated antibody for $1 \mathrm{~h}$ at $37^{\circ} \mathrm{C}$, and 3,3'-diaminobenzidine (DAB) was used to develop the stains. CD68 and CD163 staining was assessed according to staining intensity. The intensity was scored as $0-3$, with no staining (0), light yellow (1), pale brown (2), and dark brown (3) staining. The percentage of stained positive cells was scored 0-4, as the number of stained cells $<5 \%, 5 \%-25 \%, 50 \%-75 \%$, and $>75 \%$, respectively for the $0-4$ scores. More than 1000 cells were counted on each slide and reviewed independently three times, by two pathologists who were blinded to the patients' clinical data. Positive or negative scoring was the product of the intensity score and the positive cell score (product less than 1 means negative, otherwise positive).

\section{qRT-PCR quantification}

Total RNAs were isolated from cells using TRIzol $^{\circledR}$ reagent (Invitrogen Life Technologies, San Diego, CA, USA). One microgram of RNA was reverse-transcribed to cDNA using the PrimeScript First Strand cDNA synthesis kit (Takara Bio, Inc., Dalian, China) according to the manufacturer's instructions. The qRT-PCR was performed on an Applied Biosystems 7500 Real Time PCR system (Applied Biosystems, White Plains, 


\section{Cellular Physiology Cell Physiol Biochem 2017;42:1526-1539 and Biochemistry POblished online: July 19, $2017 \quad \begin{aligned} & \text { O 2017 The Authors. } \\ & \text { www.karger.com/cpb }\end{aligned}$ \\ Luo et al.: uc.306 Associates with Poor Prognosis in HCC}

Table 1. Primers used for quantitative real-time PCR. iNOS = inducible nitric oxide synthase; $\mathrm{bp}=$ base IL = interleukin; TGF = transforming growth factor pairs

\begin{tabular}{|c|c|c|c|}
\hline Gene & Primer sequence & $\begin{array}{l}\text { Length } \\
\text { (bp) }\end{array}$ & $\operatorname{Tm}\left({ }^{\circ} \mathrm{C}\right)$ \\
\hline uc.306 & $\begin{array}{l}\text { Forward: 5'-GTTAATGGAAGCCTTGGATAGGA-3' } \\
\text { Reverse: 5'-CCAAATGGTTCAGCTTGACAGA-3' }\end{array}$ & 117 & 58 \\
\hline IL10 & $\begin{array}{l}\text { Forward: 5'-GATGCCTTCAGCAGAGTGAA-3' } \\
\text { Reverse: 5'-CCCAGGTAACCCTTAAAGTCC-3' }\end{array}$ & 100 & 59 \\
\hline TGF $\beta$ & $\begin{array}{l}\text { Forward: 5'-GGATAACACACTGCAAGTGG-3', } \\
\text { Reverse: 5'- GAGCTGAAGCAATAGTTGGTG-3' }\end{array}$ & 179 & 60 \\
\hline IL 12 & $\begin{array}{l}\text { Forward:5'-TTGCCTAAATTCCAGAGAGA-3' } \\
\text { Reverse: 5'- AGCTTTGCATTCATGGTCTTG-3' }\end{array}$ & 149 & 58 \\
\hline iNOS & $\begin{array}{l}\text { Forward:5' - CCATGTCTGGGAGCATCAC -3' } \\
\text { Reverse:5'- ATGAGCTGGGAATTCCAGATC-3' }\end{array}$ & 311 & 59 \\
\hline$\beta$-actin & $\begin{array}{l}\text { Forward:5'-GTCACCAACTGGGACGACAT-3' } \\
\text { Reverse:5'-GAGGCGTACAGGGA TAGCAC-3' }\end{array}$ & 208 & 57 \\
\hline
\end{tabular}

NY, USA). The $\beta$-actin mRNA was used as internal control. All reactions were run in triplicate, with the qPCR conditions as follows: 40 cycles of $95^{\circ} \mathrm{C}$ for $5 \mathrm{~min}, 95^{\circ} \mathrm{C}$ for $10 \mathrm{sec}, 58^{\circ} \mathrm{C}-60^{\circ} \mathrm{C}$ for $35 \mathrm{sec}$, followed by one cycle of $95^{\circ} \mathrm{C}$ for $15 \mathrm{sec}, 60^{\circ} \mathrm{C}$ for $60 \mathrm{sec}$, and $95^{\circ} \mathrm{C}$ for $15 \mathrm{sec}$. All data were normalized to $\beta$-actin mRNA. All primers are listed in Table 1.

\section{Statistical analysis}

Statistical analyses were performed using SPSS, version 16.0 software (SPSS, Chicago, IL, USA). All graphs were created using GraphPad Prism 5 software (GraphPad Software, La Jolla, CA, USA). All data from three independent experiments were expressed as mean \pm SD. Differences were assessed by two-tailed Student's $t$-tests. A P $<0.05$ was considered statistically significant.

\section{Results}

\section{M1 and M2 phenotype identification}

The M1 and M2 phenotypes were identified before the IncRNA microassay. The U937 cells were pre-treated with PMA and stimulated with IL4 and IL13, to induce the M2 phenotype. M2 was identified by the high expression of IL10 and TGF- $\beta$ in M2 cells, with low expressions in M1 cells (Fig. 1A). The M2 cells were polarized into the M1 phenotype by stimulation with IFN gamma, and the M1 phenotype was verified by the high expression of IL12 and iNOS mRNA in M1 cells, which showed low or zero expression in M2 cells (Fig. 1A).

\section{LncRNA microarray analysis}

The U937 cells were stimulated to become M2 and M1 macrophages. Three duplicate samples of M1 and M2 cells were used to extract the total RNA. The Arraystar Human LncRNA Microarray V3.0, which is designed for the global profiling of human lncRNAs and protein-coding transcripts, was used to analyze the expression of lncRNAs. A total of 26,276 lncRNAs were obtained and clustered in two phenotypes (M1 and M2) of U937 cells (Fig. 1B, C). Further analyses showed that 2,977 lncRNAs belonging to T-UCRs were differentially expressed, among which 257 T-UCRs were differentially expressed (154 upregulated and 103 downregulated; q value $<0.05$; fold change $>1.5$ ) during the differentiation from the M2 to the M1 phenotype (Fig. 1C). Six types of IncRNAs, the bidirectional, intergenic, intron sense-overlapping, exon sense-overlapping, intron antisense, and natural antisense, were found in the 257 T-UCRs (Fig. 1D), of which the intergenic lncRNAs were the most abundant (62 upregulated T-UCRs and 70 downregulated T-UCRs), followed by the natural antisense, and exon sense-overlapping lncRNAs in both up- and downregulated T-UCRs.

The top ten up- and downregulated T-UCRs (picked up from the 257 T-UCRs), respectively, were grouped as shown in Fig. 2A, B, and showed that uc.306 had a higher normalized intensity in the M1 than in the M2 cells. We then analyzed the functions of the target genes of the 


\section{Cellular Physiology Cell Physiol Biochem 2017;42:1526-1539

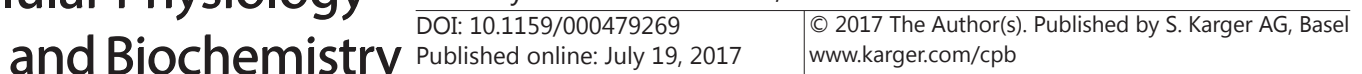

Luo et al.: uc.306 Associates with Poor Prognosis in HCC
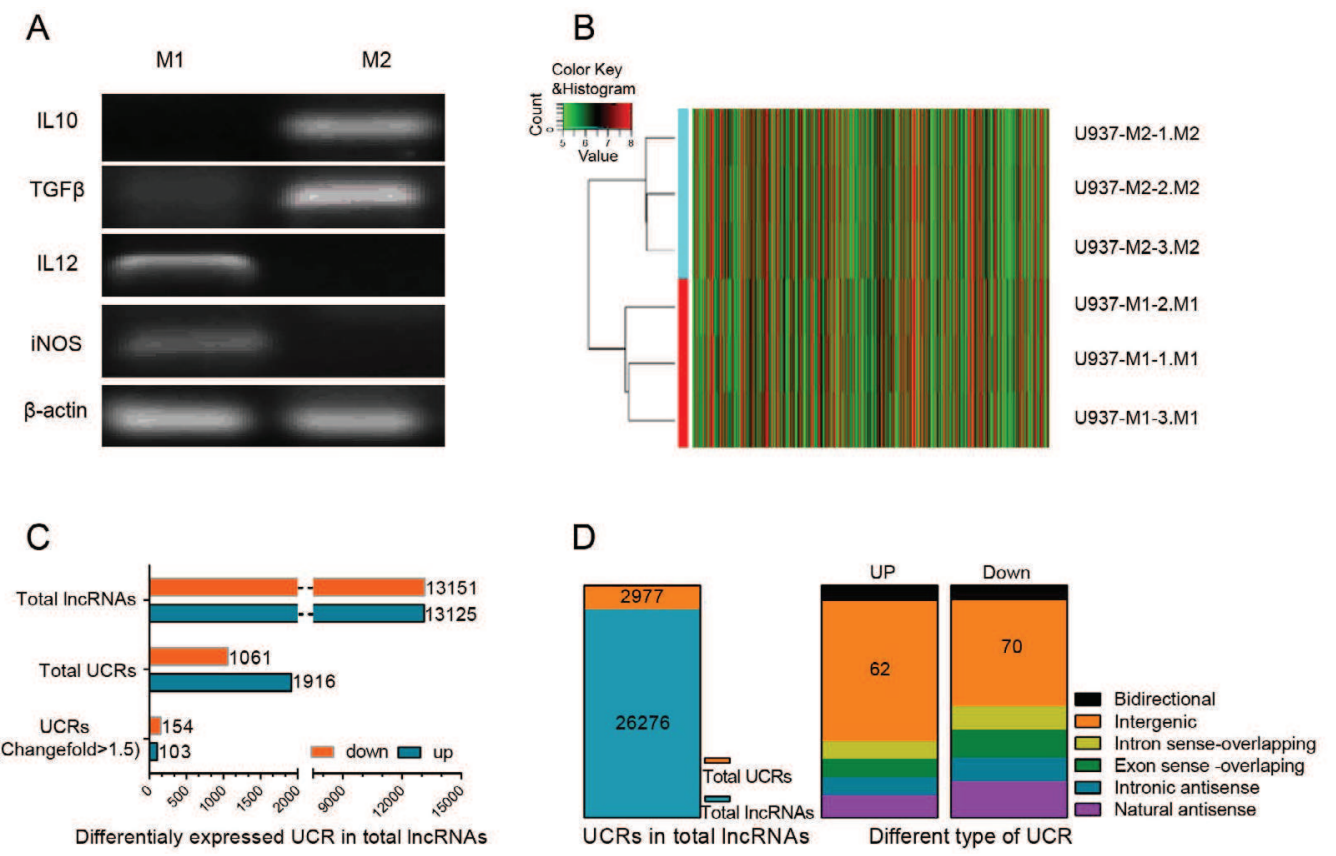

Fig. 1. Acquisition of lncRNA data including T-UCRs from M1 and M2 macrophages. (A) Gene expressions of M1/M2 phenotype markers in M1 and M2 differentiated U937 cells by qPCR. IL10 and TGF $\beta$ increased in M2 cells, while IL12 and iNOS increased in M1 cells. (B) Heat map of microassay results representing the differentially expressed lncRNAs during polarization from M2 to M1 macrophages. Three independent samples of each phenotype were used to perform the microassay. (C) Statistics of the differentially expressed IncRNAs and T-UCRs. D. Number of different types of T-UCRs.

A

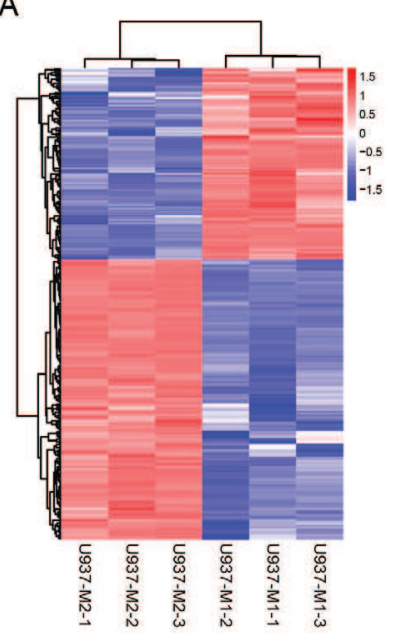

B

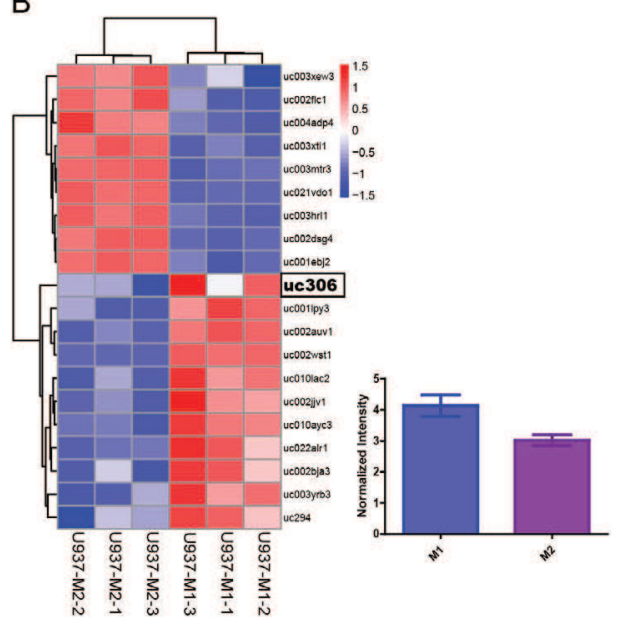

Fig. 2. Heat map of differentially expressed UCRs during the differentiation from the M2 to the M1 phenotype of U937 cells. (A) A total number of 2,977 UCRs were obtained, among which there were 275 UCRs differentially expressed (q value $<0.05$; fold change $>1.5$ ). (B) The top ten up- and downregulated UCRs were clustered, respectively, including the target T-UCR, uc.306. The column represents the normalized intensity of uc.306 between the M1 and M2 cells as determined by microassay analyses.

top ten T-UCRs and found that these genes were involved in 18 biological processes, among which the "regulation of insulin secretion," "lipid metabolic processes," "signal transduction," "positive regulation of phagocytosis," and "neuromuscular process controlling" were the top five categories (Fig. 3A). Target gene prediction of uc.306 showed that it is partly overlapped 

Cellular Physiology Cell Physiol Biochem 2017;42:1526-1539 \begin{tabular}{l|l|l|l|} 
DOI: 10.1159/000479269 & O 2017 The Author(s). Published by S. Karger AG, Basel
\end{tabular}

Luo et al.: uc.306 Associates with Poor Prognosis in HCC

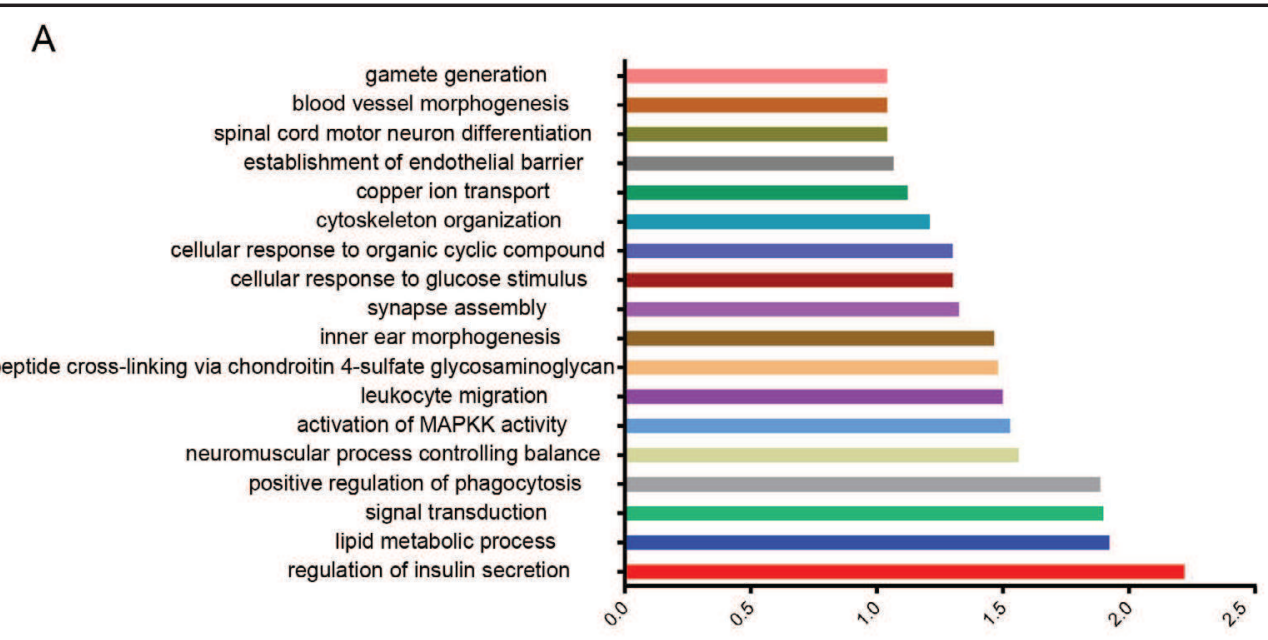

B

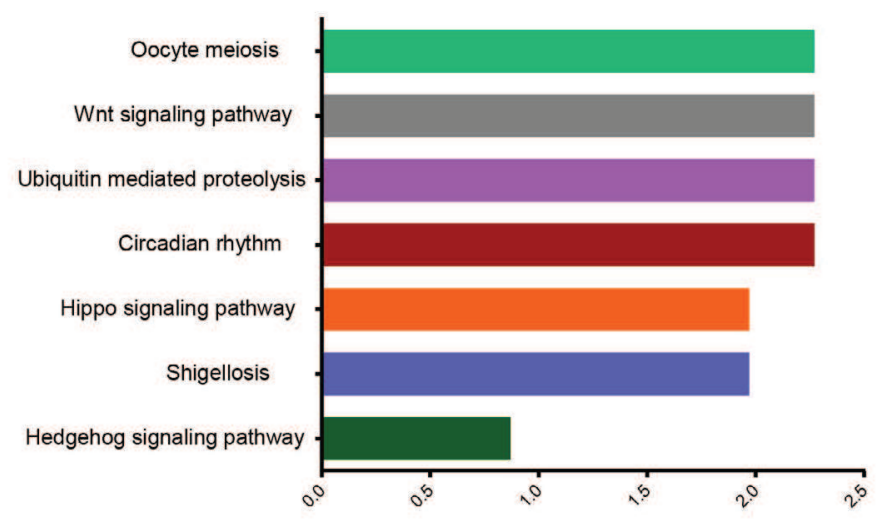

C

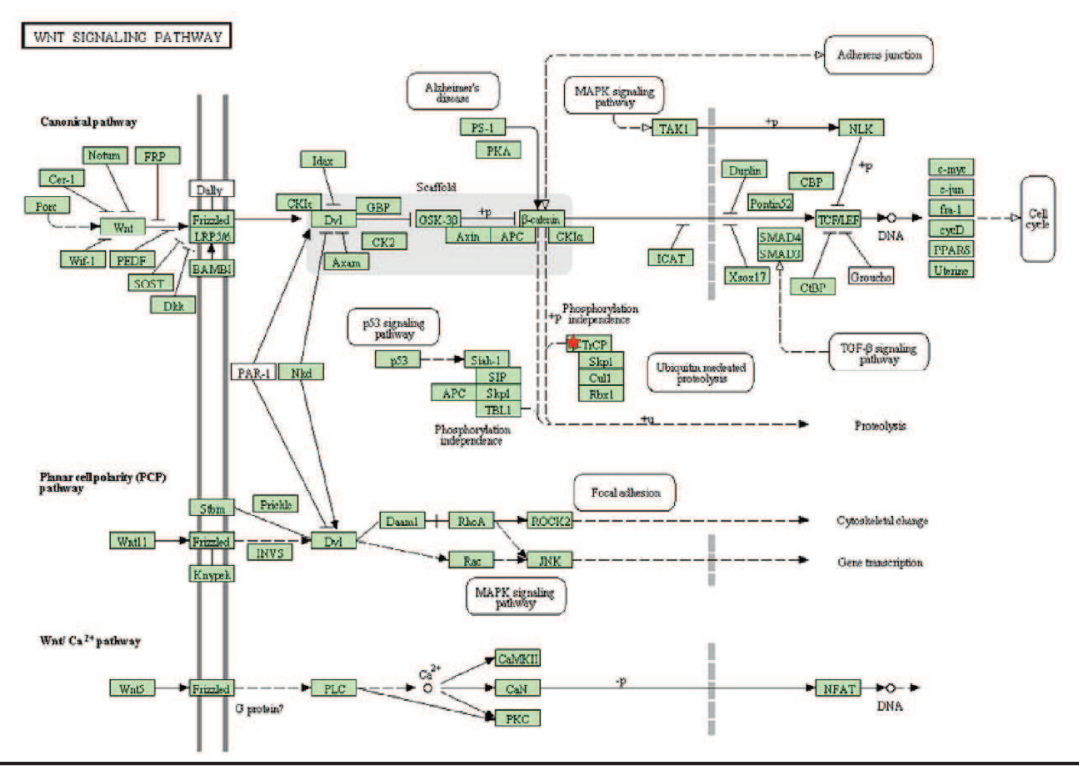

Fig. 3. The function annotations of the top ten T-UCRs and uc.306. (A) DAVID function annotation for the top ten up-and downregulated T-UCRs. The vertical axis shows the annotated functions of the target genes. The horizontal axes shows $-\log _{10}$ transformed $P$ values. (B) KEGG pathways of the uc.306 associated gene (BTRC). The vertical axis shows the annotated functions of the target genes. The horizontal axes shows $\log _{10}$ transformed $P$ values. (C) One of the most important pathways mediated by the uc.306 associated gene (BTRC) is shown. The red star refers to the $B T R C$ gene. 


\section{Cellular Physiology Cell Physiol Biochem 2017;42:1526-1539 and Biochemistry \begin{tabular}{c|l} 
DOI: 10.1159/000479269 2017 The Author(s). Published by S. Karger AG, Basel \\
\cline { 2 - 3 }
\end{tabular} \\ Luo et al.: uc.306 Associates with Poor Prognosis in HCC}

Table 2. Correlation between UC.306 expression and clinicopathological features of HBV-related HCC patients $(\mathrm{n}=252)$. OR = Odds Ratio; $95 \%$ $\mathrm{CI}=95 \%$ confidence interval; MST = median survival time; $\mathrm{HR}=$ Hazard Ratio, HCC = hepatocellular carcinoma; HBV = hepatitis B Virus; AFP = alpha fetoprotein; BCLC = Barcelona Clinic Liver Cancer; Ref. $=$ Reference. ${ }^{*}$ HR and $P$ values for univariate survival analyses. Median expression level in HCC tissues was used as the cutoff. Statistical analyses were carried out using Pearson $\div^{2}$ test. $P<0.05$ indicates statistical significance

\begin{tabular}{|c|c|c|c|c|c|c|c|}
\hline \multirow{2}{*}{ Variables } & \multicolumn{4}{|c|}{ UC.306 expression } & \multicolumn{3}{|c|}{ Survival analysis } \\
\hline & Low $(n=216)$ & High $(n=36)$ & OR $(95 \% \mathrm{Cl})$ & $P$ & Patients & $H R^{*}(95 \% \mathrm{Cl})$ & $p^{*}$ \\
\hline Sex & & & & 0.159 & & & 0.202 \\
\hline Female & 24 & 7 & Ref. & & 31 & Ref. & \\
\hline Male & 192 & 29 & $0.52(0.21-1.31)$ & & 221 & $1.81(0.73-4.53)$ & \\
\hline Age (years) & & & & 0.945 & & & 0.038 \\
\hline$<60$ & 179 & 30 & Ref. & & 209 & Ref. & \\
\hline$\geq 60$ & 37 & 6 & $0.97(0.38-2.49)$ & & 43 & $0.38(0.15-0.95)$ & \\
\hline Size $(\mathrm{cm})$ & & & & 0.618 & & & 0.011 \\
\hline$<5 \mathrm{~cm}$ & 69 & 10 & Ref. & & 79 & Ref. & \\
\hline$\geq 5 \mathrm{~cm}$ & 147 & 26 & $1.22(0.56-2.67)$ & & 173 & $2.42(1.23-4.76)$ & \\
\hline Number & & & & 0.39 & & & 0.287 \\
\hline$<3$ & 196 & 31 & Ref. & & 227 & Ref. & \\
\hline$\geq 3$ & 20 & 5 & $1.58(0.55-4.52)$ & & 25 & $1.50(0.71-3.16)$ & \\
\hline Tumor capsule & & & & 0.917 & & & 0.011 \\
\hline Complete & 124 & 21 & Ref. & & 145 & Ref. & \\
\hline Incomplete/absent & 92 & 15 & $0.96(0.47-1.97)$ & & 107 & $1.93(1.16-3.20)$ & \\
\hline Lymph node metastasis & & & & 0.172 & & & 0.001 \\
\hline No & 195 & 35 & Ref. & & 230 & Ref. & \\
\hline Yes & 21 & 1 & $0.27(0.04-2.04)$ & & 22 & $3.05(1.59-5.86)$ & \\
\hline Vascular invasion & & & & 0.790 & & & $<0.0001$ \\
\hline No & 137 & 22 & Ref. & & 159 & Ref. & \\
\hline Yes & 79 & 14 & $1.10(0.53-2.28)$ & & 93 & $3.38(2.02-5.64)$ & \\
\hline Microvascular invasion & & & & 0.086 & & & 0.001 \\
\hline No & 87 & 20 & Ref. & & 107 & Ref. & \\
\hline Yes & 129 & 16 & $0.54(0.27-1.10)$ & & 145 & $2.65(1.48-4.74)$ & \\
\hline AFP & & & & 0.111 & & & 0.102 \\
\hline$<400$ & 109 & 13 & Ref. & & 122 & Ref. & \\
\hline$\geq 400$ & 107 & 23 & $1.80(0.87-3.74)$ & & 130 & $1.53(0.92-2.54)$ & \\
\hline BCLC stage & & & & 0.959 & & & $<0.0001$ \\
\hline $0+A$ & 95 & 16 & Ref. & & 111 & Ref. & \\
\hline$B+C$ & 121 & 20 & $0.98(0.48-2.00)$ & & 141 & $3.52(1.91-6.49)$ & \\
\hline UC. 306 expression & & & & NA & & & 0.030 \\
\hline Low & 216 & 0 & & & 216 & Ref. & \\
\hline High & 0 & 36 & & & 36 & $0.33(012-0.90)$ & \\
\hline
\end{tabular}

with BTRC gene, which encode a beta-transducin repeat containing (BTRC) protein, namely $\beta-\operatorname{TrCP}$ protein. $\beta$-TrCP protein can recognize $\beta$-catenin (CTNNB1), which is one of the key molecules in the Wnt pathway, and participates in three key pathways correlated to cancer regulation, including the Wnt signaling pathway, the Hippo signaling pathway, and the Hedgehog signaling pathway (Fig. 3B, C). To further identify whether uc.306 interacts with BTRC $(\beta$-TrCP), the online program RPISeq was carried out and the interaction possibility between uc306 and BTRC was predicted to be strong positive with high RF and SVM values ( 0.85 and 0.99 , respectively), and this was verified by Western blotting in experiment that the uc.306 was overexpressed in HepG2 cells and it turned out the $\beta$-TrCP protein expression was down-regulated (data not shown).

CD163 ${ }^{+}$M2 macrophages were mainly found in HCC tissues, while high levels of CD68 ${ }^{+}$M1 macrophages were found in the adjacent normal tissues

Previous studies showed that the M1 and M2 status in cancer might influence the outcome of patients. In this study, we showed that uc.306 was highly upregulated in M1 cells, while it was downregulated in M2 U937cells. We therefore determined if the M2 and M1 phenotypes in our clinical samples had similar M2/M1 status as that of previous studies, by IHC using CD163 and CD68 as the indicators, respectively. The results showed that in 90 paired HCC tissues and corresponding adjacent normal tissues, the $\mathrm{CD}_{68}^{+}$macrophages (M1 


\section{Cellular Physiology Cell Physiol Biochem 2017;42:1526-1539 \begin{tabular}{l|l} 
DOI: 10.1159/000479269 & $\begin{array}{l}\text { @ 2017 The Author(s). Published by S. Karger AG, Basel } \\
\text { www.karger.com/cpb }\end{array}$ \\
\hline
\end{tabular}}

Luo et al.: uc.306 Associates with Poor Prognosis in HCC

Fig. 4. Immunohistochemical staining analysis and uc.306 quantification in HCC tissues and corresponding adjacent normal tissues. (A) Ninety paired HCC tissues and corresponding adjacent normal tissues were used to perform the immunohistochemical analyses. The primary antibodies, CD68 (1:200 dilution) and CD163 (1:100 dilution), were used to stain the M1 and M2 macrophages, respectively. The images represent the distribution patterns of the M1 and M2 cells in HCC tissues and adjacent normal tissues, and were taken at $200 \times$. More than 1000 cells for each slide were counted by two pathologists, blinded to the patient clinical data, and the slides were reviewed independently, three times. (B) Relative expression of uc.306 in HBV-related HCC tissues compared with corresponding adjacent liver tissues. Thirty paired HCC and adjacent normal tissues were examined by quantitative real-time PCR. Three independent experiments were examined for each sample. Differences were assessed by the two-tailed Student's $t$-test.

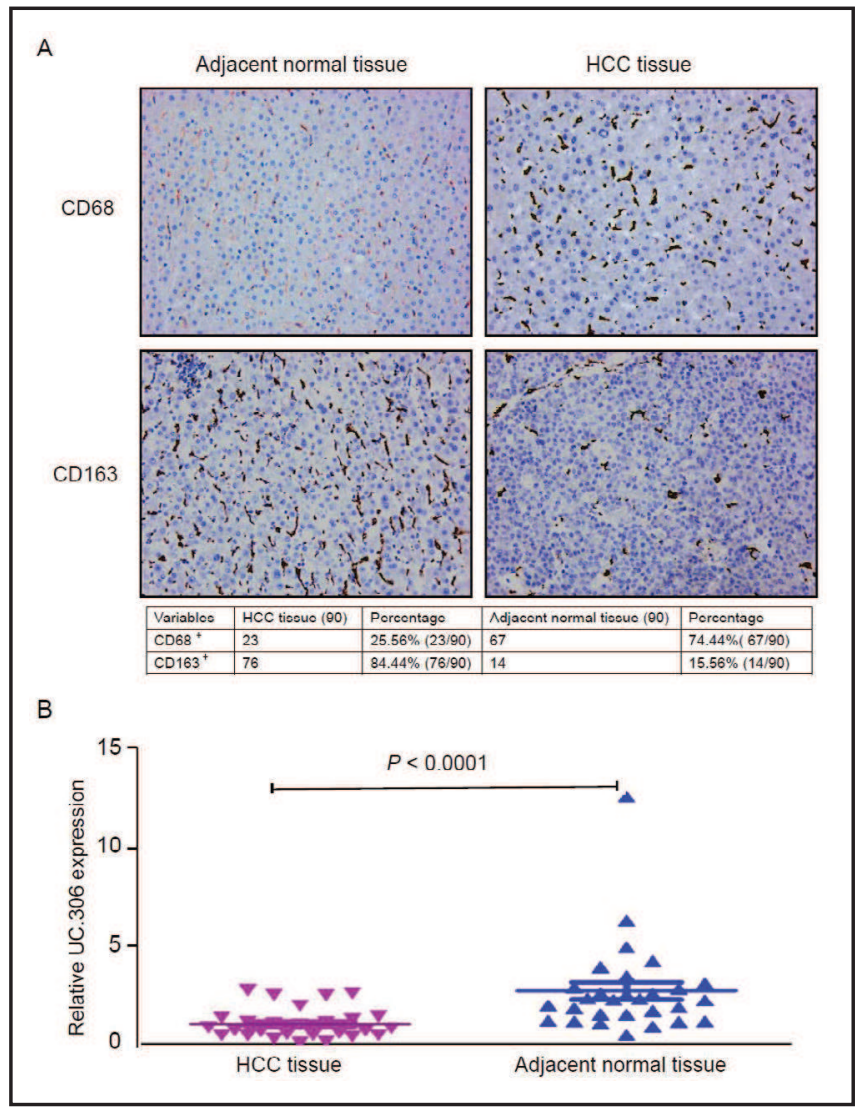

phenotype) were mainly found in the adjacent normal tissues, which occupied $74.44 \%$ of the whole tissues. However, although the $\mathrm{CD} 163^{+}$macrophages (M2 phenotype) occupied a large proportion of the HCC tissues $(84.44 \%)$, only a small number of adjacent normal tissues were CD163 positive (15.56\%) (Fig. 4A).

\section{Decreased uc.306 expression in HCC tissue predicted a better prognosis in HBV-related HCC patients}

The expression levels of uc.306 in HCC tissues and their peritumor tissues were detected in 30 paired HCC patients, and the results showed that the levels of uc.306 in HCC tissues were significantly downregulated compared with that of the corresponding adjacent normal tissues $(P<0.0001)$ (Fig. 4B). To validate these results, we then evaluated uc.306 expression in $252 \mathrm{HBV}$-related HCC and 252 corresponding adjacent normal tissues by qRT-PCR. The expression was categorized into two groups depending on whether it was downregulated or upregulated when compared to the corresponding adjacent normal tissues. The results showed that the numbers of patients with lower levels of uc.306 were much greater than those with high level of uc.306 (Fig. 5A), and the corresponding adjacent normal tissues usually had a higher expression of uc.306 compared to that of the HCC tissues $(P<0.0001$, Fig. 5B). To further examine the prognostic prediction role of uc.306 in HCC patients, KaplanMeier survival curves were used and the results showed that the expression of uc.306 was closely related to the OS of the patients $(P=0.0214$, Fig. 5C), and the lower expression of uc.306 predicted a worse prognosis when compared to the patients with higher expression of uc.306. In summary, HBV-related HCC patients with low uc.306 expression had a poorer OS compared to patients with high uc.306 levels.

Patient characteristics and clinical predictors

The impact of uc.306 expression on some clinicopathological features of HCC patients was analyzed and is shown in Table 2. Overall, 36 female HCC patients and 216 male HCC 


\section{Cellular Physiology Cell Physiol Biochem 2017;42:1526-1539 and Biochemistry Published onine: July 19, $2017 \quad \begin{aligned} & \text { O 2017 The Author(s). Published by S. Karger AG, Basel } \\ & \text { www.karger.com/cpb }\end{aligned}$}

Luo et al.: uc.306 Associates with Poor Prognosis in HCC

Table 3. Survival of UC.306 positive patients with HBV-related HCC. The median expression level in HCC tissues was used as the cutoff. All results were adjusted using Cox hazards models. $P<0.05$ was considered statistically significant. *Adjusted for age, size, tumor capsule, lymph node metastasis, vascular invasion, microvascular invasion, and UC.306 expression. HR = Hazard ratio; 95\% CI = 95\% confidence interval; MST = median survival time; Ref. = Reference

\begin{tabular}{|c|c|c|c|c|c|c|}
\hline Variables & Patients & MST(months) & Crude HR (95\% CI) & $P$ & Adjusted HR* (95\%CI) & $P^{*}$ \\
\hline Age (years) & & & & 0.038 & & 0.046 \\
\hline$<60$ & 209 & 17 & Ref. & & Ref. & \\
\hline$\geq 60$ & 43 & 20 & $0.38(0.15-0.95)$ & & $0.39(0.16-0.98)$ & \\
\hline Size $(\mathrm{cm})$ & & & & 0.011 & & 0.401 \\
\hline$<5 \mathrm{~cm}$ & 79 & 18 & Ref. & & Ref. & \\
\hline$\geq 5 \mathrm{~cm}$ & 173 & 17 & $2.42(1.23-4.76)$ & & $1.38(0.65-2.89)$ & \\
\hline Tumor capsule & & & & 0.011 & & 0.101 \\
\hline Complete & 145 & 21 & Ref. & & Ref. & \\
\hline Incomplete/absent & 107 & 13 & $1.93(1.16-3.20)$ & & $1.54(0.92-2.57)$ & \\
\hline Lymph node metastasis & & & & 0.001 & & 0.006 \\
\hline No & 230 & 18 & Ref. & & Ref. & \\
\hline Yes & 22 & 12 & $3.05(1.59-5.86)$ & & $2.51(1.30-4.87)$ & \\
\hline Vascular invasion & & & & 0.000 & & 0.000 \\
\hline No & 159 & 18 & Ref. & & Ref. & \\
\hline Yes & 93 & 16 & $3.38(2.02-5.64)$ & & $3.51(2.10-5.86)$ & \\
\hline Microvascular invasion & & & & 0.001 & & 0.236 \\
\hline No & 107 & 19 & Ref. & & Ref. & \\
\hline Yes & 145 & 17 & $2.65(1.48-4.74)$ & & $1.45(0.78-2.70)$ & \\
\hline UC.306 expression & & & & 0.030 & & 0.023 \\
\hline Low & 216 & 17 & Ref. & & Ref. & \\
\hline High & 36 & 21 & $0.33(012-0.90)$ & & $0.30(0.11-0.85)$ & \\
\hline
\end{tabular}

Fig. 5. Uc.306 expression in 252 paired HCC and adjacent normal tissues. (A) The HCC patients were classified into a high uc.306 expression group and a low uc.306 expression group according to the median value of relative uc.306 expression in HCC tissues. Each experiment was performed in triplicate. (B) Relative expression level of uc.306 in HCC tissues and adjacent normal tissues. In total, 252 paired HCC and adjacent normal tissues were used to measure the uc.306 expression level. Differences were assessed by the two-tailed Student's $t$-test. (C) The median expression level in HCC tissues was used as the cutoff, and Kaplan-Meier analysis was used to evaluate the role of uc.306 for the prognosis of HCC patients.

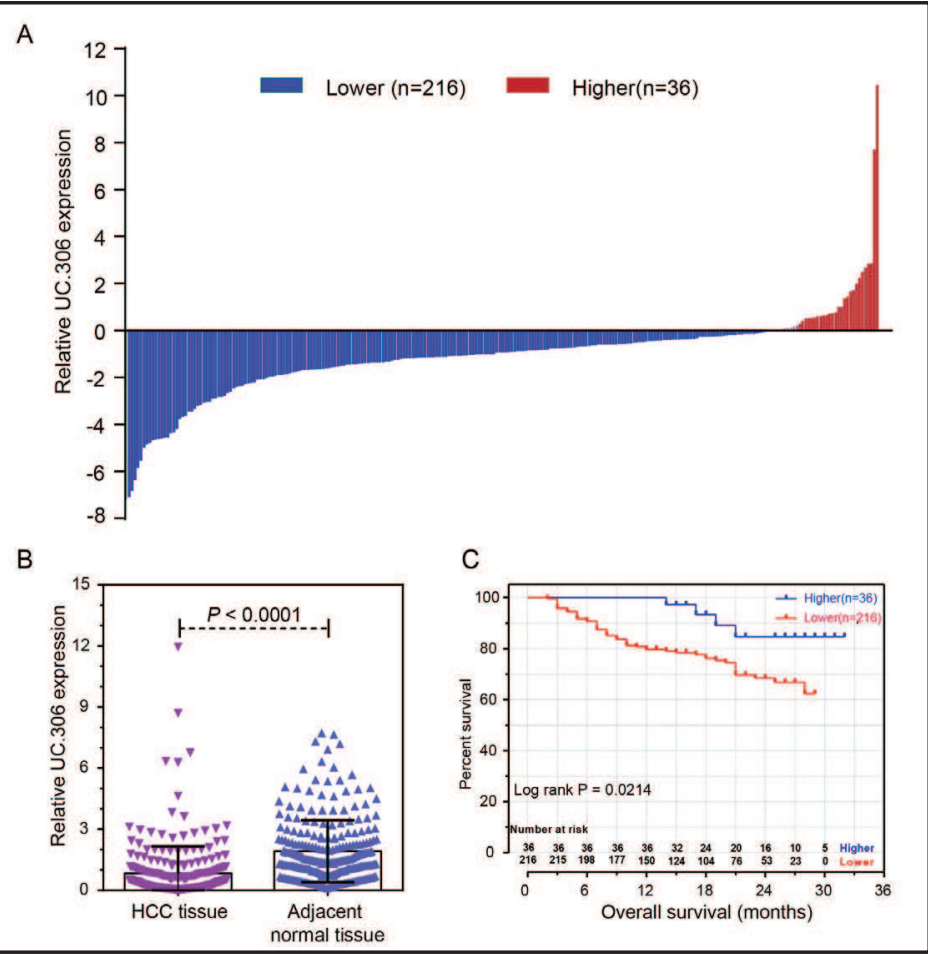

patients were included, and the results showed that the sex, tumor size, number, lymph node metastasis index, vascular invasion, and AFP level were not significantly different between the high and low uc.306 expression groups (Table 2). Univariate analyses indicated that age [hazard ratio $(\mathrm{HR})=0.38 ; 95 \%$ confidence interval $(\mathrm{CI})=0.15-0.95 ; \mathrm{P}=0.038$ ], tumor size (HR $=2.42 ; 95 \% \mathrm{CI}=1.23-4.76 ; P=0.011)$, tumor capsule $(\mathrm{HR}=1.93 ; 95 \% \mathrm{CI}=1.16-3.2 ; P=$ $0.011)$, lymph node metastasis ( $\mathrm{HR}=3.050 ; 95 \% \mathrm{CI}=1.59-5.86 ; P=0.011)$, vascular invasion $(\mathrm{HR}=3.38 ; 95 \% \mathrm{CI}=2.02-5.64 ; P=0.000)$, microvascular invasion $(\mathrm{HR}=2.65 ; 95 \% \mathrm{CI}=1.48-$ $4.74 ; P=0.001)$, $\mathrm{BCLC}$ stage $(\mathrm{HR}=3.52 ; 95 \% \mathrm{CI}=1.91-6.49 ; P=0.000)$, and uc.306 expression 
(HR $=0.33 ; 95 \% \mathrm{CI}=0.12-0.90: P=0.030)$ were correlated with the OS of HCC patients, showing that older patient ( $\geq 60$ years of age), smaller tumor size $(<5 \mathrm{~cm})$, complete tumor capsule, no lymph node metastasis, no vascular invasion, no microvascular invasion, BCLC stage A, and higher uc.306 were associated with longer survival times (Table 2). Multivariate analyses showed that age ( $\mathrm{HR}=0.39 ; 95 \% \mathrm{CI}=0.16-0.98 ; P=0.046)$, lymph node metastasis $(\mathrm{HR}=2.51 ; 95 \% \mathrm{CI}=1.30-4.87 ; P=0.006)$, vascular invasion $(\mathrm{HR}=3.51 ; 95 \% \mathrm{CI}=2.10-5.86$; $P=0.000)$, and uc.306 expression ( $\mathrm{HR}=0.30 ; 95 \% \mathrm{CI}=0.11-0.85 ; P=0.023)$ contributed to the OS of HCC patients, showing similar trends with that of the univariate analyses (Table 3 ).

\section{Discussion}

The numbers of macrophages involved in tumor angiogenesis, invasion, and metastasis correlated with the transformation from the M1 to the M2 phenotype, and the outcome was dependent on the status of M1 or M2 in cancer tissues or corresponding adjacent normal tissues. A greater number of M2 cells in tumor tissues correlated with a poorer outcome for the patients, while more M1 cells indicated a better prognosis [17,21]. This was supported by our data showing that $\mathrm{CD} 163^{+} \mathrm{M} 2$ macrophages mainly were found in HCC tissues, while $\mathrm{CD} 8^{+} \mathrm{M} 1$ macrophages were highly expressed in the adjacent normal tissues. The results from the samples in our study supported the use of uc.306 that upregulated in M1 cells and downregulated in M2 cells for the prognosis of HCC patients. Because our microassay data showed uc.306 was higher in M1 cells, which was reported to be more recruited around cancer and detrimental to cancer development, but lower in M2 cells, which was reported to be more recruited in cancer and benefit to cancer survival. The target gene of uc.306 was predicted to be BTRC, encoding $\beta$-TrCP protein that recognizes $\beta$-catenin (CTNNB1), one of the key molecules in the Wnt pathway. As known, the Wnt pathway is closely related to EMT progress, implying uc.306 might be involved in EMT via BTRC ( $\beta$-TrCP)-Wnt pathway. So, we supposed that there was a correlation between uc.306 expression and the phenotypic status of the macrophages, thus confirming the validity of our hypothesis. However, how uc.306 regulates HCC metastasis is yet unclear.

Recently, many molecules have been reported to be prognostic and diagnostic significance for HCC [27-32]. Specially, non-coding RNAs including microRNA and long non-coding RNA (lncRNA) have been reported to be more prominent in the past five years. For example, miR-361-5p could inhibit HCC growth and miR-335 would be associated with treatment response to trans-arterial chemoembolization and prognosis in HCC patients [33, 34], and IncRNAs including DGCR5, HULC and linc00152 were reported to be novel biomarkers in predicting diagnosis and diagnosis of HCC $[35,36]$. Therefore, it is reasonable that T-UCRs (as one special type of IncRNAs) containing ultra-conserved elements have been reported to be potential biomarker for diagnosis and diagnosis of cancers. Moreover, T-UCRs could be altered in human carcinomas $[14,15]$. For example, T-UCRs silencing was involved in the methylation of CpG islands in the promoter regions of some cancer cell lines [37, 38]. In addition, some T-UCRs (uc.63, uc.73,uc.206, uc.106, uc.134, and uc.475) could be regulated by hypoxia [39], and could regulate cell proliferation and apoptosis [14]. Moreover, uc.63 overexpression was reported to correlate with poor prognosis in a luminal A subgroup of breast cancer patients [40], and uc.73 levels indicated a positive correlation with overall survival [41]. These reports provided evidence that T-UCRs might play key roles in different aspects of cancer biology, as oncogenes or tumor suppressor genes.

However, to the best of our knowledge, the expression profile of T-UCRs in the polarization of macrophages is still unknown and the role in tumor biology and prognosis remain unknown. In the present study, a total number of 2,977 T-UCRs were obtained during the polarization from the M2 to the M1 phenotype of U937 cells, with 1,061 downregulated genes and 1,916 upregulated genes. Furthermore, 257 T-UCRs had a fold change $>1.5$. During the polarization of M2 to M1 macrophages, the large numbers of differentially expressed T-UCRs suggested that T-UCRs might play very important roles. In the current study, the 


\section{Cellular Physiology Cell Physiol Biochem 2017;42:1526-1539 and Biochemistry Published online: July 19, $2017 \quad \begin{aligned} & \text { D 2017 The Authors. } \\ & \text { www.karger.com/cpb }\end{aligned}$}

Luo et al.: uc.306 Associates with Poor Prognosis in HCC

function of uc.306, one of the most upregulated T-UCRs in M1 phenotype macrophages, was shown to involve the Wnt signaling pathway, the Hippo signaling pathway, and the Hedgehog signaling pathway. These pathways have been implicated in HCC formation, growth, migration, metastasis, and epithelial-mesenchymal transition (EMT) [42-44]. Therefore, uc.306 may play a role in HCC development. Our results showed that uc.306 plays a role in HCC metastasis, because the overexpression of uc.306 suppressed the migration of SMMC7721 cells when compared to that of HepG2 cells (data not shown).

Although the role of uc.306 in HCC remains unknown, its prognostic value for HCC patients should be studied. For this propose, the full length $640 \mathrm{bp}$ uc.306 was obtained by RACE amplification (data not shown). In the future, qPCR and functional examination should be feasible. We found that uc.306 was expressed not only in all of the six HCC cell lines (HL7702, QGY7703, SMMC-7721, HepG2, Huh7, and HCCLM3; data not shown), but also was significantly upregulated in adjacent normal tissues compared to HCC tissues in 30 paired patients. Further verification was performed in $252 \mathrm{HCC}$ tissues and paired adjacent normal tissues, which was consistent with the microassay outcome showing uc.306 was expressed at significantly higher levels in M1 cells compared to that of M2 cells $(P=0.045$, fold change $=2.0$ ). This implies that the expression profile of uc.306 in different macrophage phenotypes might have a positive correlation with HCC status. More importantly, the median survival was 17 months and 21 months in the low expression and high expression groups, respectively. Low expression of uc.306 was significantly associated with a shorter OS $(P<0.05)$, implying that uc.306 might be used as a biomarker for HCC.

Although the age, tumor size, tumor capsule, lymph node metastasis, vascular invasion, microvascular invasion, and BCLC stage were significantly correlated to HR, in univariate analyses, both univariate analyses and multivariate analyses showed that younger patients ( $<60$ years), stronger lymph node metastasis, stronger vascular invasion, and lower uc.306 expression contributed to the poor OS of HCC patients. Among these risk factors, lymph node metastasis and vascular invasion were reported to be associated with HCC patient survival [45-47], which was consistent with our observations. In our study, age was likely an independent risk factor, but the HR was small, which indicated that the patients $>60$ years of age might have better prognoses than the patients $<60$ years of age. Moreover, previous reports showed that age slightly influenced the OS in 1,132 HCC patients [48]. Therefore, we excluded age as a risk factor. Regarding uc.306, its HR was similar to that of age, therefore we were unsure if it was a risk factor. Although it was strongly suggested as a risk factor by both univariate analysis and multivariate analysis, the qPCR results on 252 HCC patients and the OS curves showed that lower uc.306 expression was significantly associated with poor OS. Although our study demonstrated that uc.306 could be an independent prognostic biomarker of HCC, more studies, using a larger number of patients with longer follow-up times, and measuring the functions of uc.306 in different HCC cell lines, are needed to fully understand its function in proliferation, apoptosis, and HCC biology.

In conclusion, uc.306, expressed during macrophage polarization and expressed at significantly lower levels in HCC tissues when compared to adjacent normal tissues, has potential as a prognostic biomarker in HBV-related HCC patients, and could be a novel target for the treatment of HBV-related HCC patients.

\section{Acknowledgments}

This work was supported by grants from the National Natural Science Foundation of China (Grant no. 81160262), the Guangxi Natural Science Foundation (2011GXNSFD018032, 2016GXNSFBA380091), the Foundation of Guangxi science and Technology Department (GK2013-13-B-01 and 14124003-4), the Major national science and technology projects (2012ZX10002010001009), the Innovation Project of Guangxi Graduate Education (YCSW2017109), the Fifty-Eighth China Postdoctoral Science Foundation (2015M580764) 


\section{Cellular Physiology Cell Physiol Biochem 2017;42:1526-1539 \begin{tabular}{c|c|c|c|}
\hline DOI: 10.1159/000479269 & (c) 2017 The Author(s). Published by S. Karger AG, Basel
\end{tabular}

Luo et al.: uc.306 Associates with Poor Prognosis in HCC

and the Foundation from the key Laboratory of Early Prevention and Control of Regional High Frequence Tumor Research, Ministry of Education (GKE2015-ZZ03 and GXK201601).

\section{Disclosure Statement}

All authors declare no conflict of interest.

\section{References}

1 Forner A, Llovet JM, Bruix J: Hepatocellular carcinoma. Lancet 2012;379:1245-1255.

2 Siegel RL, Miller KD, Jemal A: Cancer statistics, 2016. CA Cancer J Clin 2016;66:7-30.

-3 Chen W, Zheng R, Baade PD, Zhang S, Zeng H, Bray F, Jemal A, Yu XQ He J: Cancer statistics in China, 2015. CA Cancer J Clin 2016;66:115-132.

4 Shiratori Y, Yoshida H, Omata M: Management of hepatocellular carcinoma: advances in diagnosis, treatment and prevention. Expert Rev Anticancer Ther 2001;1:277-290.

5 Bodzin AS, Busuttil RW: Hepatocellular carcinoma: Advances in diagnosis, management, and long term outcome. World J Hepatol 2015;7:1157-1167.

-6 Altekruse SF, McGlynn KA, Reichman ME: Hepatocellular carcinoma incidence, mortality, and survival trends in the United States from 1975 to 2005. J Clin Oncol 2009;27:1485-1491.

7 Yao H, Liu X, Chen S, Xia W, Chen X: Decreased expression of serum miR-424 correlates with poor prognosis of patients with hepatocellular carcinoma. Int J Clin Exp Pathol 2015;8:14830-14835.

8 Lan T, Chang L, Rahmathullah MN, Wu L, Yuan YF: Comparative Efficacy of Interventional Therapies for Early-stage Hepatocellular Carcinoma: A PRISMA-compliant Systematic Review and Network Metaanalysis. Medicine (Baltimore) 2016;95:e3185.

-9 Abdelsalam ME, Murthy R, Avritscher R, Mahvash A, Wallace MJ, Kaseb AO, Odisio BC: Minimally invasive image-guided therapies for hepatocellular carcinoma. J Hepatocell Carcinoma 2016;3:55-61.

10 Reichl P, Mikulits W: Accuracy of novel diagnostic biomarkers for hepatocellular carcinoma: An update for clinicians (Review). Oncol Rep 2016;36:613-625.

11 Lin XJ, Chong Y, Guo ZW, Xie C, Yang XJ, Zhang Q, Li SP, Xiong Y, Yuan Y, Min J, Jia WH, Jie Y, Chen MS, Chen MX, Fang JH, Zeng C, Zhang Y, Guo RP, Wu Y, Lin G, Zheng L, Zhuang SM: A serum microRNA classifier for early detection of hepatocellular carcinoma: a multicentre, retrospective, longitudinal biomarker identification study with a nested case-control study. Lancet Oncol 2015;16:804-815.

12 Bejerano G, Lowe CB, Ahituv N, King B, Siepel A, Salama SR, Rubin EM, Kent WJ, Haussler D: A distal enhancer and an ultraconserved exon are derived from a novel retroposon. Nature 2006;441:87-90.

-13 Calin GA, Liu CG, Ferracin M, Hyslop T, Spizzo R, Sevignani C, Fabbri M, Cimmino A, Lee EJ, Wojcik SE, Shimizu M, Tili E, Rossi S, Taccioli C, Pichiorri F, Liu X, Zupo S, Herlea V, Gramantieri L, Lanza G, Alder H, Rassenti L, Volinia S, Schmittgen TD, Kipps TJ, Negrini M, Croce CM: Ultraconserved regions encoding ncRNAs are altered in human leukemias and carcinomas. Cancer Cell 2007;12:215-229.

14 Li Q, Li X, Wang C: Uc.206 regulates cell proliferation and apoptosis by targeting P53 in cervical cancer cells. Neoplasma 2016;63:411-418.

-15 Braconi C, Valeri N, Kogure T, Gasparini P, Huang N, Nuovo GJ, Terracciano L, Croce CM, Patel T: Expression and functional role of a transcribed noncoding RNA with an ultraconserved element in hepatocellular carcinoma. Proc Natl Acad Sci USA 2011;108:786-791.

16 Wang C, Yan G, Zhang Y, Jia X, Bu P: Long non-coding RNA MEG3 suppresses migration and invasion of thyroid carcinoma by targeting of Rac1. Neoplasma 2015;62:541-549.

-17 Locati M, Mantovani A, Sica A: Macrophage activation and polarization as an adaptive component of innate immunity. Adv Immunol 2013;120:163-184.

18 Kreider T, Anthony RM, Urban JF, Jr., Gause WC: Alternatively activated macrophages in helminth infections. Curr Opin Immunol 2007;19:448-453.

19 Sica A, Mantovani A: Macrophage plasticity and polarization: in vivo veritas. J Clin Invest 2012;122:787795. 


\section{Cellular Physiology Cell Physiol Biochem 2017;42:1526-1539 \begin{tabular}{l|l} 
DOI: 10.1159/000479269 & $\begin{array}{l}\text { O 2017 The Author(s). Published by S. Karger AG, Basel } \\
\text { www.karger.com/cpb }\end{array}$ \\
\hline
\end{tabular}}

Luo et al.: uc.306 Associates with Poor Prognosis in HCC

20 Smith TD, Tse MJ, Read EL, Liu WF: Regulation of macrophage polarization and plasticity by complex activation signals. Integr Biol (Camb) 2016;8:946-955.

-21 Mantovani A, Sica A: Macrophages, innate immunity and cancer: balance, tolerance, and diversity. Curr Opin Immunol 2010;22:231-237.

-22 Rolny C, Mazzone M, Tugues S, Laoui D, Johansson I, Coulon C, Squadrito ML, Segura I, Li X, Knevels E, Costa S, Vinckier S, Dresselaer T, Akerud P, De Mol M, Salomaki H, Phillipson M, Wyns S, Larsson E, Buysschaert I, Botling J, Himmelreich U, Van Ginderachter JA, De Palma M, Dewerchin M, Claesson-Welsh L, Carmeliet P: HRG inhibits tumor growth and metastasis by inducing macrophage polarization and vessel normalization through downregulation of PIGF. Cancer Cell 2011;19:31-44.

23 Lewis CE, Pollard JW: Distinct role of macrophages in different tumor microenvironments. Cancer Res 2006;66:605-612.

24 Mahmoud SM, Lee AH, Paish EC, Macmillan RD, Ellis IO, Green AR: Tumour-infiltrating macrophages and clinical outcome in breast cancer. J Clin Pathol 2012;65:159-163.

-25 Hu Y, He MY, Zhu LF, Yang CC, Zhou ML, Wang Q Zhang W, Zheng YY, Wang DM, Xu ZQ, Wu YN, Liu LK: Tumor-associated macrophages correlate with the clinicopathological features and poor outcomes via inducing epithelial to mesenchymal transition in oral squamous cell carcinoma. J Exp Clin Cancer Res 2016;35:12.

-26 Yang J, Zhang Z, Chen C, Liu Y, Si Q, Chuang TH, Li N, Gomez-Cabrero A, Reisfeld RA, Xiang R, Luo Y: MicroRNA-19a-3p inhibits breast cancer progression and metastasis by inducing macrophage polarization through downregulated expression of Fra-1 proto-oncogene. Oncogene 2014;33:3014-3023.

-27 Han C, Yu L, Liu X, Yu T, Qin W, Liao X, Liu Z, Lu S, Chen Z, Su H, Zhu G, Qin X, Gui Y, Li J, Xiao K, Chen X, Ye X, Peng M, Dong J, Peng T: ATXN7 Gene Variants and Expression Predict Post-Operative Clinical Outcomes in Hepatitis B Virus-Related Hepatocellular Carcinoma. Cell Physiol Biochem 2016;39:2427-2438.

28 Jing W, Luo P, Zhu M, Ai Q Chai H, Tu J: Prognostic and Diagnostic Significance of SDPR-Cavin-2 in Hepatocellular Carcinoma. Cell Physiol Biochem 2016;39:950-960.

29 Hang X, Zhu S, Di H, Wu Z, Chu K, Wang J, Xin H, Yu G, Peng H, Miao X, Xu W: NEDD4 Depletion Inhibits Hepatocellular Carcinoma Growth via Targeting PTEN. Cell Physiol Biochem 2016;39:768-779.

-30 Wang Y, Liu T, Tang W, Deng B, Chen Y, Zhu J, Shen X: Hepatocellular Carcinoma Cells Induce Regulatory T Cells and Lead to Poor Prognosis via Production of Transforming Growth Factor-beta1. Cell Physiol Biochem 2016;38:306-318.

-31 Fan JL, Yang YF, Yuan CH, Chen H, Wang FB: Circulating Tumor Cells for Predicting the Prognostic of Patients with Hepatocellular Carcinoma: A Meta Analysis. Cell Physiol Biochem 2015;37:629-640.

-32 Li C, Chen J, Zhang K, Feng B, Wang R, Chen L: Progress and Prospects of Long Noncoding RNAs (lncRNAs) in Hepatocellular Carcinoma. Cell Physiol Biochem 2015;36:423-434.

-33 Sun JJ, Chen GY, Xie ZT: MicroRNA-361-5p Inhibits Cancer Cell Growth by Targeting CXCR6 in Hepatocellular Carcinoma. Cell Physiol Biochem 2016;38:777-785.

-34 Cui L, Hu Y, Bai B, Zhang S: Serum miR-335 Level is Associated with the Treatment Response to TransArterial Chemoembolization and Prognosis in Patients with Hepatocellular Carcinoma. Cell Physiol Biochem 2015;37:276-283.

- 35 Huang R, Wang X, Zhang W, Zhangyuan G, Jin K, Yu W, Xie Y, Xu X, Wang H, Sun B: Down-Regulation of LncRNA DGCR5 Correlates with Poor Prognosis in Hepatocellular Carcinoma. Cell Physiol Biochem 2016;40:707-715.

36 Li J, Wang X, Tang J, Jiang R, Zhang W, Ji J, Sun B: HULC and Linc00152 Act as Novel Biomarkers in Predicting Diagnosis of Hepatocellular Carcinoma. Cell Physiol Biochem 2015;37:687-696.

-37 Lujambio A, Portela A, Liz J, Melo SA, Rossi S, Spizzo R, Croce CM, Calin GA, Esteller M: CpG island hypermethylation-associated silencing of non-coding RNAs transcribed from ultraconserved regions in human cancer. Oncogene 2010;29:6390-6401.

-38 Hudson RS, Yi M, Volfovsky N, Prueitt RL, Esposito D, Volinia S, Liu CG, Schetter AJ, Van Roosbroeck K, Stephens RM, Calin GA, Croce CM, Ambs S: Transcription signatures encoded by ultraconserved genomic regions in human prostate cancer. Mol Cancer 2013;12:13.

-39 Ferdin J, Nishida N, Wu X, Nicoloso MS, Shah MY, Devlin C, Ling H, Shimizu M, Kumar K, Cortez MA, Ferracin M, Bi Y, Yang D, Czerniak B, Zhang W, Schmittgen TD, Voorhoeve MP, Reginato MJ, Negrini M, Davuluri RV, Kunej T, Ivan M, Calin GA: HINCUTs in cancer: hypoxia-induced noncoding ultraconserved transcripts. Cell Death Differ 2013;20:1675-1687. 


\section{Cellular Physiology Cell Physiol Biochem 2017;42:1526-1539 \begin{tabular}{l|l|l|l}
\hline DOI: 10.1159/000479269 2017 The Author(s). Published by S. Karger AG, Basel \\
\hline
\end{tabular}

Luo et al.: uc.306 Associates with Poor Prognosis in HCC

40 Marini A, Lena AM, Panatta E, Ivan C, Han L, Liang H, Annicchiarico-Petruzzelli M, Di Daniele N, Calin GA, Candi E, Melino G: Ultraconserved long non-coding RNA uc.63 in breast cancer. Oncotarget DOI:10.18632/ oncotarget.10572.

41 Sana J, Hankeova S, Svoboda M, Kiss I, Vyzula R, Slaby 0: Expression levels of transcribed ultraconserved regions uc.73 and uc.388 are altered in colorectal cancer. Oncology 2012;82:114-118.

-42 Kim W, Khan SK, Yang Y: Interacting network of Hippo, Wnt/beta-catenin and Notch signaling represses liver tumor formation. BMB Rep 2017;50:1-2.

43 Fan WH, Du FJ, Liu XJ, Chen N: Knockdown of FRAT1 inhibits hypoxia-induced epithelial-to-mesenchymal transition via suppression of the Wnt/beta-catenin pathway in hepatocellular carcinoma cells. Oncol Rep 2016;36:2999-3004.

44 Ye Y, Long X, Zhang L, Chen J, Liu P, Li H, Wei F, Yu W, Ren X, Yu J: NTS/NTR1 co-expression enhances epithelial-to-mesenchymal transition and promotes tumor metastasis by activating the Wnt/beta-catenin signaling pathway in hepatocellular carcinoma. Oncotarget DOI:10.18632/oncotarget.11854.

45 Zhang L, Xiang ZL, Zeng ZC, Fan J, Tang ZY, Zhao XM: A microRNA-based prediction model for lymph node metastasis in hepatocellular carcinoma. Oncotarget 2016;7:3587-3598.

-46 Lee DY, Park JW, Kim TH, Lee JH, Kim BH, Woo SM, Kim SS, Lee WJ, Kim DY, Kim CM: Prognostic indicators for radiotherapy of abdominal lymph node metastases from hepatocellular carcinoma. Strahlenther Onkol 2015;191:835-844.

-47 Hsu HT, Sung MT, Lee CC, Kuo YJ, Chi CW, Lee HC, Hsia CY: Peroxisome Proliferator-Activated Receptor gamma Expression Is Inversely Associated with Macroscopic Vascular Invasion in Human Hepatocellular Carcinoma. Int J Mol Sci 2016;17(8).pii:E1226.

48 Tan JT, Zhao C, Peng NF, Yang Y, Zhong JH, Yang T, Zheng MH, Wang YY, Gong WF, Xiang BD, Li LQ: Association between age and overall survival of patients with hepatocellular carcinoma after hepatic resection. J Surg Oncol DOI:10.1002/jso.24434. 